\title{
Article \\ Mental Health Status of Healthcare Professionals and Students of Health Sciences Faculties in Kuwait during the COVID-19 Pandemic
}

\author{
Zahra Alsairafi $^{1, *(D)}$, Abdallah Y. Naser ${ }^{2}\left(\mathbb{D}\right.$, Fatemah M. Alsaleh $^{1}$, Abdelmoneim Awad ${ }^{1}$ (D) and Zahraa Jalal ${ }^{3}(\mathbb{D}$ \\ 1 Department of Pharmacy Practice, Faculty of Pharmacy, Kuwait University, Kuwait City 12037, Kuwait; \\ fatemah.alsaleh@ku.edu.kw (F.M.A.); abdelmouneim.awadhussein@ku.edu.kw (A.A.) \\ 2 Department of Pharmaceutical Sciences and Clinical Pharmacy, Isra University, Amman 33, Jordan; \\ abdallah.naser@iu.edu.jo \\ 3 School of Pharmacy, Institute of Clinical Sciences, University of Birmingham, Edgbaston B15 2TT, UK; \\ z.jalal@bham.ac.uk \\ * Correspondence: zahra.alsairafi@ku.edu.kw
}

check for

updates

Citation: Alsairafi, Z.; Naser, A.Y.; Alsaleh, F.M.; Awad, A.; Jalal, Z.

Mental Health Status of Healthcare

Professionals and Students of Health Sciences Faculties in Kuwait during the COVID-19 Pandemic. Int. J. Environ. Res. Public Health 2021, 18 , 2203. https://doi.org/10.3390/ ijerph18042203

Academic Editor: Paul Tchounwou

Received: 3 February 2021

Accepted: 19 February 2021

Published: 23 February 2021

Publisher's Note: MDPI stays neutral with regard to jurisdictional claims in published maps and institutional affiliations.

Copyright: (c) 2021 by the authors. Licensee MDPI, Basel, Switzerland. This article is an open access article distributed under the terms and conditions of the Creative Commons Attribution (CC BY) license (https:/ / creativecommons.org/licenses/by/ $4.0 /)$.

\begin{abstract}
Objectives: This study aimed to assess the impact of the COVID-19 pandemic on the mental health status of healthcare professionals (HCPs) and undergraduate students in the health sciences center (HSCUs). In addition, it explored the factors associated with the increased levels of mental health burden among the study population. Methods: A cross-sectional study was performed using two online-administered questionnaires: the Patient Health Questionnaire (PHQ-9) and the Generalized Anxiety Disorder 7-item (GAD-7), which were distributed in parallel to HCPs and HSCUs in Kuwait. These instruments are validated assessment scales to assess mental health status: depression (PHQ-9) and anxiety (GAD-7). Statistical analyses were carried out using SPSS- version 25. Results: A total of 857 individuals ( 559 HCPs and 298 HSCUs) participated in this study. The prevalence of moderately severe depression or severe depression (PHQ-9 total score of $\geq 15$ ) among respondents was $66.6 \%$. The median (interquartile range, IQR) PHQ-9 score was significantly higher among HSCUs (20 \{11.5\}) compared to HCPs $(17\{8\})$. The prevalence of severe anxiety (GAD-7 total score of $\geq 15$ ) among respondents was $36.7 \%$. There were no significant differences between the median (IQR) GAD-7 scores among the HCPs $(14\{7\})$ and HSCUs $(13\{8\})$. Binary logistic regression analysis revealed that three variables were significantly and independently associated with severe depression among HCPs. The prevalence of severe depression was found to be greater among females compared to males. In addition, it was significantly lower among those who were aged $\geq 50$ years, and those who reported that they were not in direct contact with COVID-19 patients. Among HSCUs, females showed greater depression than males. In contrast, those aged $>29$ years and who had no history of chronic disease showed lower depression compared to their counterparts in the 18-29 years age group and who had a chronic disease history. Conclusions: The COVID-19 pandemic had a significant negative impact on the mental health of HCPs and HSCUs in Kuwait. This highlights the need for proactive efforts to support their mental health and well-being through educational campaigns and psychological support programs.
\end{abstract}

Keywords: coronavirus disease; COVID-19; mental health; healthcare professionals; students; depression; anxiety; survey; Kuwait

\section{Introduction}

The coronavirus disease 2019 (COVID-19) is an illness caused by a novel beta-coronavirus, named the severe acute respiratory syndrome coronavirus 2 (SARS-CoV-2). It appeared firstly in Wuhan, China in December 2019, and then spread rapidly worldwide, leading to a fatal pandemic. SARS-CoV-2 infection appears to cause a wide range of symptoms, including asymptomatic infection, mild infections of the upper respiratory tract, severe 
viral pneumonia, respiratory failure, multiple organ failure, and death. Mortality rates are higher among older adults, particularly those with chronic diseases [1]. Due to its highly contagious nature, it is transmitted through respiratory droplets and close contact with infected people [2]. Consequently, governments have taken strict measures such as isolating infected humans and their family members, cancelling public transportation, implementing travel restrictions, curfews and social distancing, and obligating people to wear face masks [3]. In Kuwait, as of 1 February 2021, a total of 165,257 diagnosed cases of COVID-19 had been reported, with 959 deaths, 157,931 recovered cases, and 6367 cases undergoing treatment [4]. Since the identification of the first few cases of COVID-19 in Kuwait in February 2020, the government applied precautionary measures similar to those seen globally to prevent the spread of the disease. In addition to the country lockdown, the Kuwaiti government applied strict discipline to people violating the imposed measures, such as 3 months jail and fines of 30,000 Kuwaiti dinars (USD 98,610).

The public healthcare system in Kuwait is divided into primary, secondary, and tertiary care. Primary care is delivered through general and specialized polyclinics distributed across five healthcare regions. Secondary care is provided through six general hospitals, and tertiary care is delivered through fifteen specialized centers [5]. During the COVID-19 outbreak, some of the healthcare settings operated regularly, while others provided units for the management of patients with COVID-19. The Ministry of Health (MOH) also imposed that all healthcare professionals (HCPs) are obliged to be on duty and prohibited any leave during this ongoing pandemic, in order to control the situation and prevent the collapse of the healthcare system. The health sciences center of Kuwait University includes five faculties: medicine, dentistry, pharmacy, allied health sciences, and public health. During the COVID-19 outbreak, education at Kuwait University was suspended (from February until July 2020) and no alternate measures were implemented to resume education during this period. It has been proposed that such restrictive measures would have resulted in short- and long-term adverse consequences, such as stress-related psychiatric symptoms like anxiety and depressive mood among the affected people [6].

The sudden surge of increased work at the treatment front-line, the threat of being infected and transmitting the virus to family members, and the consequent death or illness of a relative or friend due to the pandemic could have had a psychological impact on people working in the health sector, especially the HCPs who have direct or indirect contact with COVID-19 patients [7-9]. In addition, this pandemic could have had a negative impact on university students who lived with a high degree of pressure and fears about the future due to the suspension of education [10]. In this context, recent studies have shown that the global growth in the number of cases and deaths, the collapse of the healthcare system in many countries, and the subsequent lack of effective medical treatment are factors prompting public fear, anxiety, and/or depression, which is usually neglected during pandemic management [11-13]. Thus, studying the psychological wellbeing of populations during the COVID-19 pandemic is paramount. This is particularly the case in Kuwait, where around one-quarter and one-third of the general public showed anxiety and depressive symptoms during this pandemic, respectively [14], and the majority of students $\mathbf{( 9 0 . 9 \% )}$ ) at Kuwait University reported moderate to high life stress [15]. Therefore, this study aimed to assess the impact of the COVID-19 pandemic on the mental health status of people who are at high risk of being affected. For example, it is vital to evaluate the mental health burden on HCPs who experienced increased working hours, feelings of incapability, and self-isolation from families. Unlike the general public, people working in the health sector perceive a risk of acquiring the virus at work due to suspected cases and, hence, are more likely to experience depression and anxiety [14]. As future health professionals, this study also included undergraduate students in the health sciences center (HSCUs). In addition, this study explored the factors associated with the increased levels of mental health burden among the study population, in order to recommend targeted interventions and support. 


\section{Materials and Methods}

\subsection{Study Area and Design}

Kuwait is a Middle Eastern country with an area of $17,820 \mathrm{~km}^{2}$ and a population of 4,301,539 people (2020 estimate) [16]. A quantitative, prospective, and cross-sectional study was performed to assess the mental health status of HCPs and HSCUs during the COVID-19 outbreak. It was conducted between May and July 2020. Ethical approval for this study was obtained from the Human Ethical Committee, Health Sciences Centre, Kuwait University (VDR/EC/3655).

\subsection{Study Population}

The sample size was estimated based on the World Health Organization (WHO) recommendations for the minimal sample size needed for a prevalence study [17]. Using a confidence interval of $95 \%$, a standard deviation of 0.5 , and a margin of error of $5 \%$, the required sample size was 385 participants. A convenience sample of eligible participants (HCPs and HSCUs) was invited to participate in the study. Data were collected using two online-administered questionnaires sent through various social media platforms (e.g., Twitter and WhatsApp). Each study population was invited using a specific survey-link (e.g., one for the HCPs and another for HSCUs). All HCPs $(n=9863)$ who work at the six generalized hospitals, which provided units for COVID-19 patients during the pandemic, were invited [18]. The hospitals were approached by the researcher. The head of each department (e.g., medical/pharmacy/nursing) in these hospitals were visited to help in obtaining WhatsApp addresses of HCPs and distributing the survey-link to them. For HSCUs, the researcher used the official Twitter address of the HSC of Kuwait University to invite them to participate in the study. In addition, one staff member at each faculty invited students in his/her contact list through WhatsApp messages. The inclusion criteria were an age of $\geq 18$ years, living in Kuwait during the pandemic period, and working in governmental hospitals that were operated for the management of COVID-19 patients for HCPs, and studying at HSC of Kuwait University for HSCUs. The study objectives, maintenance of confidentiality, and anonymity were clearly explained at the beginning of the survey. A reminder message was sent to all eligible participants before the end of the data collection period (on 1st of July). All participants voluntarily participated in the study and gave written consent.

\subsection{Study Questionnaires}

Previously validated assessment scales, the Patient Health Questionnaire (PHQ-9) and the Generalized Anxiety Disorder 7-item (GAD-7) were used to assess depression and anxiety among the study's participants. The study instruments have been used among different populations to assess their mental health status [19-22]. The PHQ-9 and GAD-7 instruments asked the participants about the degree of applicability of each item (question), using a 4-point Likert scale. Participants' responses ranged from 0 to 3, where 0 means "Not at all" and 3 means "Nearly every day". The PHQ-9 is a self-report questionnaire that is commonly used as a screening tool for depression [23]. It is a 9-question instrument to assess the presence and severity of depression [24,25]. Items are scored from 0 to 3 generating a total score ranging from 0 to 27 . A total score of $0-4$ indicates minimal depression, 5-9 mild depression, 10-14 moderate depression, 15-19 moderately severe depression, and 20-27 severe depression [26]. The GAD-7 instrument includes 7 items, and was initially developed to screen for GAD, and also proved to have good sensitivity and specificity as a screening tool for anxiety, panic, and social disorders [27,28]. Items are scored from 0 to 3 generating a total score ranging from 0 to 21 . A total score of $0-4$ indicates minimal anxiety, 5-9 mild anxiety, 10-14 moderate anxiety, and 15-21 severe anxiety [29].

The prevalence rates of depression and anxiety were determined using a cut-off point as recommended by the authors of the PHQ-9 and GAD-7 scales. In this study, depression was defined as a total score of 15 or more, which indicates moderately severe or severe 
depression. Anxiety was defined as a total score of 15 or more, which indicates severe anxiety. The rates were estimated by dividing the number of participants who exceeded the borderline score (15) by the total number of participants in the same population. In addition, demographic information was collected from the participants, such as age, gender, and marital status. All participants were asked whether they were worried about being infected with COVID-19 or transmitting it to family members (yes/no question). Moreover, HCPs were asked about whether they were in direct contact and/or were providing direct or indirect medical care for patients with COVID-19 during this pandemic. Students were asked about their years of study and history of chronic diseases. The questionnaires were pre-tested for content, design, readability, and comprehension on two HCPs and three HSCUs, and minor modifications were included.

\subsection{Data Analysis}

Descriptive statistics were used to describe participants' demographics. Continuous data were reported as median (interquartile range, IQR). Categorical data were reported as percentages ( $95 \%$ confidence interval, CI). Comparative analysis was performed on the depression and anxiety scores across different demographic and other characteristics of respondents using Mann-Whitney and Kruskal-Wallis tests because the data were not normally distributed based on the Shapiro-Wilk and Kolmogorov-Smirnov tests for normality. Logistic regression was used to estimate odds ratios (ORs) with 95\% CIs. Logistic regression models were carried out using anxiety or depression scores above the cut-off points for severe cases. A two-sided $p<0.05$ was considered statistically significant. The statistical analyses were carried out using the Statistical Package for Social Sciences (IBM Corp, Armonk, NY, SPSS Statistics for Windows, version 25).

\section{Results}

\subsection{Participants Characteristics}

A total of 857 responders (HCPs $=559$ and HSCUs $=298), 18$ years and above, who fully completed the questionnaire were included in the statistical analysis. Table 1 shows the characteristics of the study's participants. The majority $(n=633,73.9 \%)$ were females, married ( $n=425,49.6 \%)$, and with regards to the HCPs, most had a high income ( $n=267$, $47.8 \%)$. Physicians contributed to the largest proportion of the participating HCPs $(n=213$, $38.1 \%)$ followed by pharmacists ( $n=189,33.8 \%)$, allied health professionals $(n=127,22.7 \%)$, and nurses $(n=30,5.4 \%)$. Most of the HCPs ( $n=478,85.5 \%$; 95\% CI: 82.3-88.3) reported that they were in direct contact with COVID-19 patients during the pandemic period. In relation to HSCUs, around $33.6 \%(n=100)$ were in their early years, $48 \%(n=143)$ in the middle years, and $18.4 \%(n=55)$ in their final years. Only $15.4 \%(n=46 ; 95 \%$ CI: $11.6-20.2)$ of HSCUs reported a history of chronic disease. The majority of the participants $(n=549$, $64.1 \%$; 95\% CI: 60.7-67.3) reported that they were concerned about contracting COVID-19 or transmitting it to their family members.

\subsection{Prevalence of Depression and Anxiety}

Table 2 shows the prevalence of depression and anxiety among the respondents stratified by their severity. Two-thirds ( $n=571 ; 66.6 \% ; 95 \%$ CI: 62.9-69.3) were found to have PHQ-9 scores $\geq 15$, which indicates moderately severe depression or severe depression. The prevalence of mild, moderate, moderately severe, and severe depression among respondents were $3.2 \%, 28.2 \%, 35.1 \%$, and $31.5 \%$, respectively. Over one-third $(n=314$; $36.7 \%$; 95\% CI: 79.4-84.6) had GAD-7 scores $\geq 15$, which indicates severe anxiety. The proportions of mild, moderate, and severe anxiety among respondents were $17.8 \%, 45.5 \%$, and $36.7 \%$ respectively. 
Table 1. Characteristics of the study participants.

\begin{tabular}{|c|c|c|c|}
\hline Characteristics & $\begin{array}{c}\text { Overall }(n=857) \\
\text { Frequency }(\%)\end{array}$ & $\begin{array}{l}\text { HCPs }(n=559) \\
\text { Frequency }(\%)\end{array}$ & $\begin{array}{c}\text { HSCUs }(n=298) \\
\text { Frequency }(\%)\end{array}$ \\
\hline \multicolumn{4}{|c|}{ Gender } \\
\hline Males & $224(26.1)$ & $193(34.5)$ & $31(10.4)$ \\
\hline Females & $633(73.9)$ & $366(65.5)$ & $267(89.6)$ \\
\hline \multicolumn{4}{|c|}{ Age (Years) for HCPs } \\
\hline $18-29$ & $128(22.9)$ & $128(22.9)$ & \\
\hline $30-49$ & $355(63.5)$ & $355(63.5)$ & \\
\hline$\geq 50$ & $76(13.6)$ & $76(13.6)$ & \\
\hline \multicolumn{4}{|c|}{ Age (Years) for HSCUs } \\
\hline $18-29$ & $289(97.0)$ & & $289(97.0)$ \\
\hline$>29$ & $9(3.0)$ & & $9(3.0)$ \\
\hline \multicolumn{4}{|c|}{ Marital status } \\
\hline Single & $410(47.8)$ & $148(26.5)$ & $262(87.9)$ \\
\hline Married & $425(49.6)$ & $393(70.3)$ & $32(10.7)$ \\
\hline Divorced/Widowed & $22(2.6)$ & $18(3.2)$ & $4(1.4)$ \\
\hline \multicolumn{4}{|c|}{ Stage of study for HSCUs } \\
\hline Early years & $100(33.6)$ & & $100(33.6)$ \\
\hline Middle years & $143(48.0)$ & & $143(48.0)$ \\
\hline Final years & $55(18.4)$ & & $55(18.4)$ \\
\hline \multicolumn{4}{|c|}{ Monthly income for HCPs } \\
\hline Low $(<1000$ KWD $)$ & $175(31.3)$ & $175(31.3)$ & \\
\hline Medium (1000-1500 KWD) & 117 (20.9) & 117 (20.9) & \\
\hline High (>1500 KWD) & $267(47.8)$ & $267(47.8)$ & \\
\hline \multicolumn{4}{|c|}{ Specialty for HCPs } \\
\hline Physicians & $213(38.1)$ & $213(38.1)$ & \\
\hline Pharmacists & $189(33.8)$ & $189(33.8)$ & \\
\hline Nurses & $30(5.4)$ & $30(5.4)$ & \\
\hline Allied health professionals & $127(22.7)$ & $127(22.7)$ & \\
\hline \multicolumn{4}{|c|}{ Chronic disease history for HSCUs } \\
\hline Yes & $46(15.4)$ & & $46(15.4)$ \\
\hline No & $252(84.6)$ & & $252(84.6)$ \\
\hline \multicolumn{4}{|c|}{ In direct contact with COVID-19 patients for HCPs } \\
\hline Yes & $478(85.5)$ & $478(85.5)$ & \\
\hline No & $81(14.5)$ & $81(14.5)$ & \\
\hline \multicolumn{4}{|c|}{ Worried about being infected with COVID-19 or transmitting it to family members } \\
\hline Yes & $549(64.1)$ & $503(90.0)$ & $46(15.4)$ \\
\hline No & $308(35.9)$ & $56(10.0)$ & $252(84.6)$ \\
\hline
\end{tabular}

3.3. Comparison of Depression and Anxiety Scores across Different Characteristics of Respondents

Table 3 presents the median (IQR) scores of depression and anxiety stratified by the participants' characteristics. The median (IQR) PHQ-9 score for depression was significantly higher among HSCUs (20 \{11.5\}) compared to HCPs $(17\{8\}) ; p=0.006$ and females (18 \{9\}) compared to males (15 \{8\}); $p<0.001$. In HCPs, the median (IQR) PHQ-9 score for depression was significantly higher among those aged 18-29 years $(19\{10\})$ and 30-49 years (17 $\{8.25\})$ compared to those aged $\geq 50$ years (15 $\{8.20\}), p<0.05$. In HSCUs, the median (IQR) PHQ-9 score for depression was significantly higher among those aged 18-29 years $(20\{11.75\})$ and students with a history of chronic disease (23.5 \{8\}) compared to those aged $>29$ years $(18\{11.70\}), p=0.001$, and those with no chronic disease history (18 $\{10\}), p=0.018$, respectively. The median (IQR) GAD-7 scores for anxiety were significantly 
higher among females (14 $\{7\})$ compared to males $(12\{8\}), p<0.001$, and HSCUs with a history of chronic disease $(16.5\{2.75\})$ compared to those with no history of chronic disease (12 $\{7\}), p=0.017$. Interestingly, both populations in the age range of 18-29 years had comparable median depression and anxiety scores. The two populations had the same median anxiety score (13), whereas HSCUs showed higher median depression scores (20 $\{11.75\})$ compared to HCPs $(19\{10\}), p<0.05$.

Table 2. Prevalence of depression and anxiety among the participants stratified by severity.

\begin{tabular}{cccc}
\hline Levels of Depression and Anxiety & $\begin{array}{c}\text { Overall }(\boldsymbol{n = 8 5 7 )} \\
\text { Frequency (\%) }\end{array}$ & $\begin{array}{c}\text { HCPs }(\boldsymbol{n = 5 5 9 )} \\
\text { Frequency (\%) }\end{array}$ & $\begin{array}{c}\text { HSCUs }(\boldsymbol{n = 2 9 8 )} \\
\text { Frequency (\%) }\end{array}$ \\
\hline Depression assessment No. $(\%)$ & \\
\hline Minimal depression & $17(2.0)$ & $23(4.1)$ & $17(5.7)$ \\
\hline Mild depression & $27(3.2)$ & $180(32.2)$ & $62(1.3)$ \\
\hline Moderate depression & $242(28.2)$ & $199(35.6)$ & $102(34.2)$ \\
\hline Moderately severe depression & $301(35.1)$ & $157(28.1)$ & $113(38.0)$ \\
\hline Severe depression & $270(31.5)$ & 0 & \\
\hline Minimal anxiety & Anxiety assessment No. $(\%)$ & $44(14.8)$ \\
\hline Mild anxiety & 0 & $109(19.5)$ & $149(50.0)$ \\
\hline Moderate anxiety & $153(17.8)$ & $241(43.1)$ & $105(35.2)$ \\
\hline Severe anxiety & $390(45.5)$ & $209(37.4)$ &
\end{tabular}

Table 3. Median (interquartile range, IQR) scores of depression and anxiety stratified by participants' characteristics.

\begin{tabular}{|c|c|c|c|c|c|c|}
\hline \multirow{2}{*}{ Variable } & \multicolumn{3}{|c|}{ Depression Score } & \multicolumn{3}{|c|}{ Anxiety Score } \\
\hline & Median & IQR & $p$-Value & Median & IQR & $p$-Value \\
\hline \multicolumn{7}{|c|}{ Population } \\
\hline HCPs & 17.00 & 8.00 & \multirow{2}{*}{0.006} & 14.00 & 7.00 & \multirow{2}{*}{0.143} \\
\hline HSCUs & 20.00 & 11.50 & & 13.00 & 8.00 & \\
\hline \multicolumn{7}{|c|}{ Gender } \\
\hline Males & 15.00 & 8.00 & \multirow{2}{*}{$<0.001$} & 12.00 & 8.00 & \multirow{2}{*}{$<0.001$} \\
\hline Females & 18.00 & 9.00 & & 14.00 & 7.00 & \\
\hline \multicolumn{7}{|c|}{ Age (Years) for HCPs } \\
\hline $18-29$ & 19.00 & 10.00 & \multirow{3}{*}{0.000} & 13.00 & 7.75 & \multirow{3}{*}{0.669} \\
\hline $30-49$ & 17.00 & 8.25 & & 14.00 & 7.00 & \\
\hline$\geq 50$ & 15.00 & 8.20 & & 12.00 & 10.00 & \\
\hline \multicolumn{7}{|c|}{ Age (Years) for HSCUs } \\
\hline $18-29$ & 20.00 & 11.75 & \multirow{2}{*}{0.001} & 13.00 & 8.00 & \multirow{2}{*}{0.661} \\
\hline$>29$ & 18.00 & 11.70 & & 12.00 & 8.75 & \\
\hline \multicolumn{7}{|c|}{ Marital status } \\
\hline Single & 19.00 & 10.00 & \multirow{3}{*}{0.085} & 13.00 & 8.00 & \multirow{3}{*}{0.716} \\
\hline Married & 17.00 & 9.00 & & 14.00 & 8.00 & \\
\hline Divorced/Widowed & 18.00 & 13.00 & & 14.00 & 9.00 & \\
\hline \multicolumn{7}{|c|}{ Stage of study for HSCUs } \\
\hline Early years & 19.5 & 10.50 & \multirow{3}{*}{0.917} & 14.00 & 8.00 & \multirow{3}{*}{0.754} \\
\hline Middle years & 21.00 & 12.00 & & 16.00 & 11.00 & \\
\hline Final years & 18.00 & 7.75 & & 14.00 & 8.75 & \\
\hline
\end{tabular}


Table 3. Cont.

\begin{tabular}{|c|c|c|c|c|c|c|}
\hline \multirow{2}{*}{ Variable } & \multicolumn{3}{|c|}{ Depression Score } & \multicolumn{3}{|c|}{ Anxiety Score } \\
\hline & Median & IQR & $p$-Value & Median & IQR & $p$-Value \\
\hline \multicolumn{7}{|c|}{ Monthly income for HCPs } \\
\hline Low (<1000 KWD) & 18.00 & 10.00 & \multirow{3}{*}{0.195} & 13.50 & 7.25 & \multirow{3}{*}{0.696} \\
\hline Medium (1000-1500 KWD) & 18.00 & 10.00 & & 14.00 & 7.00 & \\
\hline High (>1500 KWD) & 17.00 & 9.25 & & 14.00 & 8.00 & \\
\hline \multicolumn{7}{|c|}{ Specialty for HCPs } \\
\hline Physicians & 18.00 & 10.00 & \multirow{4}{*}{0.326} & 13.00 & 7.00 & \multirow{4}{*}{0.631} \\
\hline Pharmacists & 17.00 & 8.00 & & 14.00 & 8.00 & \\
\hline Nurses & 18.00 & 8.50 & & 13.00 & 7.75 & \\
\hline Allied health professionals professional & 18.00 & 9.00 & & 14.00 & 8.00 & \\
\hline \multicolumn{7}{|c|}{ Chronic disease history for HSCUs } \\
\hline Yes & 23.50 & 8.00 & \multirow{2}{*}{0.018} & 16.50 & 2.75 & \multirow{2}{*}{0.017} \\
\hline No & 18.00 & 10.00 & & 12.00 & 7.00 & \\
\hline \multicolumn{7}{|c|}{ Worried about being infected with COVID-19 or transmitting it to family members } \\
\hline Yes & 16.00 & 8.00 & \multirow{2}{*}{0.809} & 14.00 & 7.00 & \multirow{2}{*}{0.650} \\
\hline No & 15.50 & 6.75 & & 13.00 & 9.50 & \\
\hline
\end{tabular}

In addition, those who worried about being infected with COVID-19 or transmitting it to their family members had higher median depression and anxiety scores. Pharmacists and HCPs with high-income levels showed lower median depression scores. Students in their final years had the least median depression and anxiety scores compared to their colleagues in other year levels. However, there were no significant associations between all those variables.

\subsection{Factors Independently Associated with the Increased Levels of Mental Health Burden}

Using logistic regression, among HCPs, the following group were identified to be at higher risk of depression: females, younger than 50 years, who reported that they were in direct contact and provided medical care to COVID-19 patients during the pandemic period (Table 4). Among HSCUs, females who are $>29$ years were at higher risk of depression, and those who reported a chronic disease history were at higher risk of depression and anxiety (Table 5).

Table 4. Logistic regression analysis for healthcare professionals (HCPs).

\begin{tabular}{ccc}
\hline Variable & OR (95\% CI) for Depression & OR (95\% CI) for Anxiety \\
\hline & Gender & \\
\hline Males (Reference) & 1.00 & 1.00 \\
\hline Females & $1.98(1.34-2.95)(p<0.01)$ & $1.45(0.97-2.18)$ \\
\hline Age $($ Years $)$ & 1.00 \\
\hline$<50$ (Reference) & 1.00 & $0.86(0.49-1.50)$ \\
\hline$\geq 50$ & $0.54(0.32-0.92)(p=0.001)$ & 1.00 \\
\hline Single (Reference) & Marital status & \\
\hline Married & 1.00 & $0.81(0.54-1.22)$ \\
\hline Divorced/Widowed & $0.89(0.59-1.35)$ & $1.71(0.63-4.64)$ \\
\hline
\end{tabular}


Table 4. Cont.

\begin{tabular}{ccc}
\hline Variable & OR (95\% CI) for Depression & OR (95\% CI) for Anxiety \\
\hline Low (<1000 KWD) (Reference) & 1.00 & 1.00 \\
\hline Medium (1000-1500 KWD) & $1.39(0.86-2.24)$ & $1.30(0.82-2.05)$ \\
\hline High (>1500 KWD) & $0.85(0.58-1.24)$ & $0.88(0.60-1.29)$ \\
\hline In direct contact with patients and provided medical care during COVID-19 pandemic \\
\hline Yes (Reference) & 1.00 & 1.00 \\
\hline No & $0.56(0.33-0.96)(p=0.033)$ & $0.95(0.55-1.63)$ \\
\hline Specialty & 1.00 \\
\hline Physicians (Reference) & 1.00 & $1.03(0.69-1.54)$ \\
\hline Pharmacists & $1.11(0.75-1.66)$ & $0.98(0.44-2.20)$ \\
\hline Nurses & $1.09(0.47-2.50)$ & $1.26(0.80-1.97)$ \\
\hline
\end{tabular}

Table 5. Logistic regression analysis for undergraduate students in the health sciences center (HSCUs).

\begin{tabular}{|c|c|c|}
\hline Variable & OR $(95 \% \mathrm{CI})$ for Depression & OR $(95 \% C I)$ for Anxiety \\
\hline \multicolumn{3}{|c|}{ Gender } \\
\hline Males (Reference) & 1.00 & 1.00 \\
\hline Females & $1.80(0.85-3.83)(p<0.01)$ & $2.23(0.83-6.00)$ \\
\hline \multicolumn{3}{|c|}{ Age (Years) } \\
\hline $18-29$ & 1.00 & 1.00 \\
\hline$>29$ & $0.26(0.15-0.44)(p=0.001)$ & $0.43(0.23-0.70)$ \\
\hline \multicolumn{3}{|c|}{ Marital status } \\
\hline Single (Reference) & 1.00 & 1.00 \\
\hline Married & $0.92(0.44-1.91)$ & $0.98(0.43-2.21)$ \\
\hline Divorced/Widowed & $0.82(0.05-13.17)$ & - \\
\hline \multicolumn{3}{|c|}{ Stage of study } \\
\hline Early years (Reference) * & 1.00 & 1.00 \\
\hline Middle years * & $1.09(0.96-1.73)$ & $1.18(0.71-1.96)$ \\
\hline Final years * & $0.88(0.55-1.43)$ & $1.04(0.61-1.76)$ \\
\hline \multicolumn{3}{|c|}{ Chronic disease history } \\
\hline Yes (Reference) & 1.00 & 1.00 \\
\hline No & $0.55(1.03-1.94)(p=0.018)$ & $0.71(0.36-1.38)$ \\
\hline
\end{tabular}

* Early years: students in 1st and 2nd years; Middle years: students in 3rd and 4th years; Final years: students in 5th, 6th, and 7th years.

\section{Discussion}

The pivotal role of HCPs during pandemics as front-liners is fundamental, and makes them more vulnerable to depression, anxiety, and stress due to overwhelmed healthcare systems and fear of being infected or transmitting the virus to their families [8,30-38]. Psychological impairment would significantly affect the attention, cognitive functioning, and clinical decision-making of HCPs [39]. Previous studies have also suggested that public health emergencies had a major psychological impact on university students expressed as anxiety, fear, and worry $[10,40,41]$. The main aim of the current study was to assess the 
impact of the COVID-19 pandemic on the mental health status of HCPs and HSCUs in Kuwait. In addition, this study explored the factors associated with the increased levels of mental health burden among the study population. It was found that the mean depression scores were significantly higher among HSCUs compared to those of HCPs. However, there were no significant differences in the median anxiety scores between the two populations. The high rates of depression and anxiety reported among this population are alarming, and appropriately targeted interventions are needed.

\subsection{Mental Health Status of HCPs}

In Japan and Singapore, during the Severe Acute Respiratory Syndrome (SARS) outbreak, fear and anxiety were prevalent among more than half of HCPs [42,43]. In Greece, nearly half of the HCPs experienced moderately high levels of worry during the H1N1 influenza pandemic [44]. In the case of COVID-19, due to its unclear dynamics, rapidity of spread, high morbidity and mortality rates, and the lack of definitive therapy and preventive vaccines, feelings of fear and stress might be exacerbated, contributing to the pressure and anxiety to HCPs $[2,6,45]$. In China, half of HCPs were identified to suffer from at least mild depression, $45 \%$ with moderate or severe anxiety, and one-third with insomnia during the COVID-19 outbreak [46]. HCPs in Oman had high anxiety rates, where $65 \%$ suffered from mild, moderate, or severe anxiety during this recent pandemic [47]. In India, HCPs also showed depression and anxiety symptoms ( $47 \%$ and $50 \%$, respectively) during the outbreak of COVID-19 [48]. Consistent with the previous studies, this study found that more than half of HCPs experienced depression and 37.4\% experienced anxiety. However, this was not the case in Saudi Arabia, where only 15\% of HCPs reported fear and anxiety or considered rescheduling their duty to avoid contact with COVID-19 patients [38] This could be attributed to the fact that in Saudi Arabia HCPs passed through several campaigns as a part of preparedness for the upcoming pandemic, to improve seasonal influenza uptake during their previous Middle East Respiratory Syndrome (MERS-COV) outbreak. In Jordan, HCPs reported lower depression and anxiety rates compared to HCPs in Kuwait [49]. This could be related to the fact that in Jordan, HCPs experienced fewer cases of COVID-19 due to the rapid proactive measures taken by the government. In Italy, only $20 \%$ of HCPs had depression symptoms and $8 \%$ had forms of anxiety during the recent COVID-19 outbreak [50]. Mental health responses to epidemics may differ due to several issues including the availability of clinical evidence, media reports, case and death rates, and the implemented isolation policies [2,34].

\subsection{Factors Associated with Depression and Anxiety among HCPs}

Unsurprisingly, this study showed that depression and anxiety were more prevalent among HCPs who were in direct contact with confirmed/suspected COVID-19 patients. Similarly, studies during the SARS outbreak and COVID-19 reported more psychiatric symptoms among HCPs who were directly exposed to patients [11,47,51-53]. Being isolated or quarantined could provoke lethargy among HCPs [6]. Furthermore, Temsah et al. (2020) reported a small percentage of anxiety and anger feelings (7.6\% and $16.6 \%$ respectively) among HCPs who worked in quarantines. In regard to the specialty of the HCP, it has been proven in previous studies that during pandemics doctors showed a lower level of anxiety compared to other HCPs $[8,46,50]$. Although the current findings showed slight differences in depression and anxiety rates, doctors reported lower levels of mental distress compared to other HCPs. However, results reported from India were in opposition those of all of the previous studies, and showed no differences between doctors and nurses in their mental distress level during the pandemic [48].

Regarding the age of HCPs, this study reported similar results to those found in Jordan and other countries, where young HCPs were more psychologically affected than others $[12,47-49,54]$. This could be attributed to the fact that young HCPs may have less experience or they may have such fear because they might be parents of children, and young people who need more attention and effort in improving their knowledge about the 
preventive measures. In comparison, older HCPs may have more experience, better coping skills, and greater knowledge about pandemics and how to deal with such emergencies, even though older people with comorbidities are particularly vulnerable to worse outcomes from COVID-19, which generate extensive worry and anxiety amongst the elderly. The level of education, training, experience, and knowledge about infectious diseases and their management could positively impact the psychological wellbeing of HCPs $[55,56]$. Although this was not investigated in the current study, belief in the preventive and control measures applied by the $\mathrm{MOH}$ could also contribute to the lower rates of depression and anxiety among HCPs [35]. Similar to recent studies, the current study reported that the female gender was a risk factor for psychological distress among HCPs during pandemics $[2,46,47,49,50,54,57]$. This could be attributed to the increased frequency of hormonal fluctuation in women, which leads to mood changes compared to men $[58,59]$. However, Chen and colleagues (2020) and Suryavanshi and colleagues (2020) reported no significant differences in depression and anxiety between male and female HCPs.

\subsection{Factors Contributed to the Mental Health Status of HSCUs}

Due to the abrupt suspension of education, with no immediate alternative plans to resume lessons, HSCUs showed high depression and anxiety rates. Students might have major concerns regarding the impact of the current emergent situation on their future education and employment [2,60]. In addition, students' psychological impairment could be related to the fact that during quarantine there was an absence of interpersonal communication $[61,62]$. Alternatively, it could be that social media use increased among students due to greater availability of free time during the lockdown, resulting in a negative affect via the updated COVID-19 news and cases. In the context of depression, the current study reported higher rates $(72.2 \%)$ than Jordan (38.5\%) and Iran (27.6\%) [41,49]. This could be related to the fact that in Jordan and Iran the universities used remote learning methods instantly, whereas in Kuwait, it took several months to decide on continuing education through distance learning. Uncertainty regarding the future and the disruption of daily routine might contribute to high depression rates [63]. Regarding anxiety, this study also reported higher results (35.2\%) than Jordan and China, where university students reported anxiety rates of $21.5 \%$ and $24.9 \%$, respectively $[10,44]$. However, medical students in Iran had comparable results for anxiety rates (38\%) to students in Kuwait [41].

In this study, all HSCUs who reported a history of chronic disease showed higher depression and anxiety scores compared to their counterparts who do not have a chronic disease. Unsurprisingly, this result could be due to the awareness of the students about the association between the severity of COVID-19 complications and the presence of chronic diseases [64]. Although the type of chronic disease was not investigated in this study, other studies reported a significant association between history of mental illness and anxiety during COVID-19 outbreak among university students $[10,65,66]$. Female students showed higher depression and anxiety rates, which is consistent with results reported in Iran [41]. A previous study in Kuwait also reported a significant difference in stress rates among female compared to male students [15]. Such findings may indicate that males and females respond variously to stressors. However, in contrast to results reported from China and other countries, male and female students showed no significant differences in their distress level during the COVID-19 outbreak [10,67].

\subsection{Implications for Future and Practice}

The findings of this study highlighted the impact of the COVID-19 pandemic on the psychological wellbeing of a very important group of the population such as HCPs (who work as front-liners) and HSCUs (who have the ambition to graduate and practice their knowledge in the health sector). These results should raise the awareness of policymakers to propose appropriate interventions that ensure the psychological wellbeing of targeted individuals during the pandemic period. Regular and intensive training for all HCPs on the readiness for pandemics is necessary to improve the experience, skills, and 
mental wellbeing of HCPs, and to help effectively manage critical situations during the pandemic $[64,68]$. Although the $\mathrm{MOH}$ was highly effective in managing manpower and workforce, and in providing medical supplies and personal protective equipment, during the outbreak, emotional support for HCPs is paramount [44,69]. Psychological support is also crucial for HSCUs, and the university should provide students with psychological assistance, such as a hotline service with psychiatrists to provide them with stress relief activities $[11,40,70]$. Future qualitative studies are required in this field to help in further exploring and addressing the needs of HCPs and HSCUs during pandemics. In addition, future research could also be conducted to compare depression and anxiety levels among HCPs who work for the management of COVID-19 patients and others who work in other settings that operate regularly during the pandemic.

\subsection{Strengths and Limitations}

To our knowledge, this is the first study in Kuwait that investigated the prevalence of depression and anxiety during the COVID-19 pandemic among important population groups (HCPs and HSCUs). It included HCPs from different specialties such as physicians, nurses, and pharmacists working in the governmental hospitals in Kuwait. In addition, data were collected during the peak of the COVID-19 pandemic, which reflects the collection of the most realistic and valid results. Furthermore, the use of previously validated assessment tools is another strength of the study.

However, there are some limitations. Limited studies have discussed the impact of this novel pandemic on mental health globally and in the Middle East, which limited the comparison of this study's findings with others. In addition, the use of an online survey for data collection may introduce some bias, where some targeted populations may have been missed, or may lead to a low response rate. However, the reason for the low response rate among HCPs could be time constraints and heavy workloads due to the current situation of the pandemic, and it was unclear why some students did not participate. Because of the cross-sectional design, potential changes in depression and anxiety levels over time could not be measured. In addition, this study assessed the prevalence of acute depression and anxiety during the pandemic period, and whether the participants had chronic depression and anxiety was not investigated.

\section{Conclusions}

The COVID-19 pandemic introduced a critical level of depression and anxiety among the population. However, some groups were intensely affected due to their work, such as HCPs, or due to the suspension of education and the potential disruption to their future, such as university students. Among HCPs, those who were in direct contact with COVID19 patients and who reported worrying about being infected or transmitting the infection to their families had higher median depression and anxiety scores. In particular, females younger than 50 years were more psychologically affected than others. Among HSCUs, young females with a history of chronic disease were more likely to experience depression and anxiety compared to others. Therefore, to alleviate the psychological impairment of targeted groups of people, hospitals are encouraged to conduct educational campaigns targeting HCPs to improve their knowledge and awareness about COVID-19, and reassure them about the effectiveness of the legitimate prevention and control measures that the $\mathrm{MOH}$ applied in providing a safe environment. In addition, HSCUs should be aware and updated about the methods that the university is planning for the continuation of education within the pandemic circumstances. Although on-line courses were targeted at students about remote learning resources, psychological interventions and pastoral support is needed to effectively and appropriately regulate students' emotions and avoid any losses during this public health emergency. 
Author Contributions: Conceptualization, Z.A. and A.Y.N.; methodology, Z.A., A.Y.N., F.M.A. and A.A; software, A.Y.N.; validation, F.M.A., A.A. and Z.J.; formal analysis, Z.A., A.Y.N. and A.A.; investigation, Z.A. and F.M.A.; resources, Z.A. and F.M.A.; data curation, Z.A. and F.M.A.; writingoriginal draft preparation, Z.A. and F.M.A.; writing—review and editing, Z.A., A.Y.N., F.M.A., A.A. and Z.J.; visualization, Z.A., A.Y.N. and F.M.A.; supervision, A.A. and Z.J.; project administration, Z.A., A.Y.N. and F.M.A.; funding acquisition, Z.J. All authors have read and agreed to the published version of the manuscript.

Funding: This research received no external funding.

Institutional Review Board Statement: The study was approved by the Health Sciences Centre Ethical Committee of Kuwait University (VDR/EC13655) on 3 May 2020.

Informed Consent Statement: Informed consent was obtained from all subjects involved in the study.

Data Availability Statement: Not applicable.

Acknowledgments: The authors would like to thank all the HCPs and HSCUs who participated or helped in the achievement of this study.

Conflicts of Interest: The authors declare no conflict of interest.

\section{References}

1. World Health Organization. Coronavirus (COVID-19). Available online: https://www.who.int/emergencies/diseases/novelcoronavirus-2019 (accessed on 15 August 2020).

2. Wang, Y.; Di, Y.; Ye, J.; Wei, W. Study on the public psychological states and its related factors during the outbreak of coronavirus disease 2019 (COVID-19) in some regions of China. Psychol. Health Med. 2021, 26, 13-22. [CrossRef]

3. Prem, K.; Liu, Y.; Russell, T.W.; Kucharski, A.J.; Eggo, R.M.; Davies, N.; Jit, M.; Klepac, P.; Flasche, S.; Clifford, S.; et al. The effect of control strategies to reduce social mixing on outcomes of the COVID-19 epidemic in Wuhan, China: A modelling study. Lancet Public Health 2020, 5, e261-e270. [CrossRef]

4. Ministry of Health (MOH). COVID 19 Updates, State of Kuwait. 2020. Available online: https://corona.e.gov.kw/En (accessed on 1 February 2021).

5. Ministry of Health $(\mathrm{MOH})$. Annual Health Report. Department of Health Information and Medical Records. Ministry of Health Kuwait. 2014. Available online: https://mussaad.medium.com/kuwait-2020-health-report-5d62412ad05a (accessed on 17 October 2020).

6. Dubey, S.; Biswas, P.; Ghosh, R.; Chatterjee, S.; Dubey, M.J.; Chatterjee, S.; Lahiri, D.; Lavie, C.J. Psychosocial impact of COVID-19. Diabetes Metab. Syndr. Clin. Res. Rev. 2020, 14, 779-788. [CrossRef]

7. Maunder, R.; Hunter, J.; Vincent, L.; Bennett, J.; Peladeau, N.; Leszcz, M.; Sadavoy, J.; Verhaeghe, L.M.; Steinberg, R.; Mazzulli, T. The immediate psychological and occupational impact of the 2003 SARS outbreak in a teaching hospital. CMAJ 2003, 168, 1245-1251. Available online: https:/ /www.ncbi.nlm.nih.gov/pmc/articles/PMC154178/ (accessed on 19 December 2020).

8. Wu, P.; Fang, Y.; Guan, Z.; Fan, B.; Kong, J.; Yao, Z.; Liu, X.; Fuller, C.J.; Susser, E.; Lu, J.; et al. The Psychological Impact of the SARS Epidemic on Hospital Employees in China: Exposure, Risk Perception, and Altruistic Acceptance of Risk. Can. J. Psychiatry 2009, 54, 302-311. [CrossRef]

9. Greenberg, N.; Docherty, M.; Gnanapragasam, S.; Wessely, S. Managing mental health challenges faced by healthcare workers during covid-19 pandemic. BMJ 2020, 368, m1211. [CrossRef] [PubMed]

10. Cao, W.; Fang, Z.; Hou, G.; Han, M.; Xu, X.; Dong, J.; Zheng, J. The psychological impact of the COVID-19 epidemic on college students in China. Psychiatry Res. 2020, 287, 112934. [CrossRef]

11. Chen, Q.; Liang, M.; Li, Y.; Guo, J.; Fei, D.; Wang, L.; He, L.; Sheng, C.; Cai, Y.; Li, X.; et al. Mental health care for medical staff in China during the COVID-19 outbreak. Lancet Psychiatry 2020, 7, e15-e16. [CrossRef]

12. Huang, Y.; Zhao, N. Generalized anxiety disorder, depressive symptoms and sleep quality during COVID-19 outbreak in China: A web-based cross-sectional survey. Psychiatry Res. 2020, 288, 112954. [CrossRef] [PubMed]

13. Zhai, Y.; Du, X. Mental health care for international Chinese students affected by the COVID-19 outbreak. Lancet Psychiatry 2020, 7, e22. [CrossRef]

14. Burhamah, W.; AlKhayyat, A.; Oroszlányová, M.; AlKenane, A.; Almansouri, A.; Behbehani, M.; Karimi, N.; Jafar, H.; AlSuwaidan, M. The psychological burden of the COVID-19 pandemic and associated lockdown measures: Experience from 4000 participants. J. Affect. Disord. 2020, 277, 977-985. [CrossRef]

15. Al-Sayegh, N.; Al-Enezi, K.; Nadar, M.; Dean, E. Health Status, Behaviors, and Beliefs of Health Sciences Students and Staff at Kuwait University: Toward Maximizing the Health of Future Health Professionals and Their Patients. Int. J. Environ. Res. Public Health 2020, 17, 8776. [CrossRef] [PubMed] 
16. World Population Review, ed 36. State of Kuwait: General Statistics Bureau World Population Prospects (2020 Revision). United Nations Population Estimates and Projections. Available online: https:/ / worldpopulationreview.com/countries/kuwaitpopulation/ (accessed on 31 December 2020).

17. Lachenbruch, P.A.; Lwanga, S.K.; Lemeshow, S. Sample Size Determination in Health Studies: A Practical Manual; World Health Organization: Geneva, Switzerland, 1991; Available online: https://apps.who.int/iris/bitstream/handle/10665/40062/92415440 58_\%28p23-p80\%29.pdf? sequence=2\&isAllowed=y (accessed on 11 June 2020).

18. Al-Fadhala, T.; Elmir, H.; Helmy, H.Z. Culture and quality in Government General Hospitals in Kuwait: Multi-method Study of their Association with the Transformational Leadership. MedRxiv 2020. [CrossRef]

19. Martin, A.; Rief, W.; Klaiberg, A.; Braehler, E. Validity of the Brief Patient Health Questionnaire Mood Scale (PHQ-9) in the general population. Gen. Hosp. Psychiatry 2006, 28, 71-77. [CrossRef] [PubMed]

20. Löwe, B.; Decker, O.; Müller, S.; Brähler, E.; Schellberg, D.; Herzog, W.; Herzberg, P.Y. Validation and Standardization of the Generalized Anxiety Disorder Screener (GAD-7) in the General Population. Med. Care 2008, 46, 266-274. [CrossRef]

21. Yoon, S.; Lee, Y.; Han, C.; Pae, C.-U.; Yoon, H.-K.; Patkar, A.A.; Steffens, D.C.; Kim, Y.-K. Usefulness of the Patient Health Questionnaire-9 for Korean Medical Students. Acad. Psychiatry 2014, 38, 661-667. [CrossRef]

22. Maurer, D.M.; Raymond, T.J.; Davis, B.N. Depression: Screening and Diagnosis. Am. Fam. Physician 2018, 98, 508-515.

23. Kroenke, K.; Spitzer, R.L.; Williams, J.B.W. The PHQ-9: Validity of a brief depression severity measure. J. Gen. Intern. Med. 2001, 16, 606-613. [CrossRef]

24. Hinz, A.; Mehnert, A.; Kocalevent, R.-D.; Brähler, E.; Forkmann, T.; Singer, S.; Schulte, T. Assessment of depression severity with the PHQ-9 in cancer patients and in the general population. BMC Psychiatry 2016, 16, 1-8. [CrossRef]

25. Ma, T.J.H.; Ma, M.F.; Johansen, C.; Wittchen, H.-U.; Faller, H.; Koch, U.; Brähler, E.; Härter, M.; Keller, M.; Schulz, H.; et al. The Hospital Anxiety and Depression Scale (HADS) and the 9-item Patient Health Questionnaire (PHQ-9) as screening instruments for depression in patients with cancer. Cancer 2017, 123, 4236-4243. [CrossRef]

26. Schwenk, T.; Terrell, L.; Harrison, R.; Tremper, A.; Valenstein, M.; Bostwick, J. UMHS Depression Guideline. Guidel. Clin. Care Ambul. 2011, 1-15. Available online: http:/ / www.med.umich.edu/1info/FHP/practiceguides/depress/depress05.pdf (accessed on 2 November 2020).

27. Esser, P.; Hartung, T.J.; Friedrich, M.; Johansen, C.; Wittchen, H.-U.; Faller, H.; Koch, U.; Härter, M.; Keller, M.; Schulz, H.; et al. The Generalized Anxiety Disorder Screener (GAD-7) and the anxiety module of the Hospital and Depression Scale (HADS-A) as screening tools for generalized anxiety disorder among cancer patients. Psycho Oncol. 2018, 27, 1509-1516. [CrossRef]

28. Kroenke, K.; Spitzer, R.L.; Williams, J.B.; Monahan, P.O.; Löwe, B. Anxiety Disorders in Primary Care: Prevalence, Impairment, Comorbidity, and Detection. Ann. Intern. Med. 2007, 146, 317-325. [CrossRef]

29. Spitzer, R.L.; Kroenke, K.; Williams, J.B.W.; Löwe, B. A Brief Measure for Assessing Generalized Anxiety Disorder. Arch. Intern. Med. 2006, 166, 1092-1097. [CrossRef]

30. Koh, D.; Lim, M.; Chia, S. SARS: Health care work can be hazardous to health. Occup. Med. 2003, 53, 241-243. [CrossRef]

31. Tam, C.W.C.; Pang, E.P.F.; Lam, L.C.W.; Chiu, H.F.K. Severe acute respiratory syndrome (SARS) in Hong Kong in 2003: Stress and psychological impact among frontline healthcare workers. Psychol. Med. 2004, 34, 1197-1204. [CrossRef]

32. Wilson, N.; Baker, M.; Crampton, P.; Mansoor, O. The potential impact of the next influenza pandemic on a national primary care medical workforce. Hum. Resour. Health 2005, 3, 7. [CrossRef] [PubMed]

33. McAlonan, G.M.; Lee, A.M.; Cheung, V.; Cheung, C.; Tsang, K.W.T.; Sham, P.C.; Chua, S.E.; Wong, J.G.W.S. Immediate and Sustained Psychological Impact of an Emerging Infectious Disease Outbreak on Health Care Workers. Can. J. Psychiatry 2007, 52, 241-247. [CrossRef] [PubMed]

34. Wong, T.W.; Yau, J.K.; Chan, C.L.; Kwong, R.S.; Ho, S.M.; Lau, C.C.; Lau, F.L.; Lit, C.H. The psychological impact of severe acute respiratory syndrome outbreak on healthcare workers in emergency departments and how they cope. Eur. J. Emerg. Med. 2005, 12, 13-18. [CrossRef]

35. Li, L.; Wan, C.; Ding, R.; Liu, Y.; Chen, J.; Wu, Z.; Liang, C.; He, Z.; Li, C. Mental distress among Liberian medical staff working at the China Ebola Treatment Unit: A cross sectional study. Health Qual. Life Outcomes 2015, 13, 156. [CrossRef] [PubMed]

36. Alsubaie, S.; Temsah, M.H.; Al-Eyadhy, A.A.; Gossady, I.; Hasan, G.M.; Al-Rabiaah, A.; Jamal, A.A.; Alhaboob, A.A.; Alsohime, F.; Somily, A.M. Middle East Respiratory Syndrome Coronavirus epidemic impact on healthcare workers' risk perceptions, work and personal lives. J. Infect. Dev. Ctries. 2019, 13, 920-926. [CrossRef] [PubMed]

37. Chen, Y.; Zhou, H.; Zhou, Y.; Zhou, F. Prevalence of self-reported depression and anxiety among pediatric medical staff members during the COVID-19 outbreak in Guiyang, China. Psychiatry Res. 2020, 288, 113005. [CrossRef]

38. Temsah, M.-H.; Al-Sohime, F.; Alamro, N.; Al-Eyadhy, A.; Al-Hasan, K.; Jamal, A.; Al-Maglouth, I.; Aljamaan, F.; Al Amri, M.; Barry, M.; et al. The psychological impact of COVID-19 pandemic on health care workers in a MERS-CoV endemic country. J. Infect. Public Health 2020, 13, 877-882. [CrossRef]

39. Leblanc, V.R. The Effects of Acute Stress on Performance: Implications for Health Professions Education. Acad. Med. 2009, 84 (Suppl. 10), S25-S33. [CrossRef] [PubMed]

40. Mei, S.L.; Yu, J.X.; He, B.W.; Li, J.Y. Psychological investigation of university students in a university in Jilin province. Med. Soc. 2011, 24, 84-86.

41. Nakhostin-Ansari, A.; Sherafati, A.; Aghajani, F.; Khonji, M.S.; Aghajani, R.; Shahmansouri, N. Depression and Anxiety among Iranian Medical Students during COVID-19 Pandemic. Iran. J. Psychiatry 2020, 15, 228-235. [CrossRef] 
42. Imai, T.; Takahashi, K.; Hasegawa, N.; Lim, M.-K.; Koh, D.; Hoshuyama, T. SARS risk perceptions in healthcare workers, Japan. Emerg. Infect. Dis. 2005, 11, 404-410.

43. Koh, D.; Lim, M.K.; Chia, S.E.; Ko, S.M.; Qian, F.; Ng, V.; Tan, B.H.; Wong, K.S.; Chew, W.M.; Tang, H.K.; et al. Risk Perception and Impact of Severe Acute Respiratory Syndrome (SARS) on Work and Personal Lives of Healthcare Workers in Singapore: What can we learn? Med. Care 2005, 43, 676-682. [CrossRef] [PubMed]

44. Goulia, P.; Mantas, C.; Dimitroula, D.; Mantis, D.; Hyphantis, T. General hospital staff worries, perceived sufficiency of information and associated psychological distress during the A/H1N1 influenza pandemic. BMC Infect. Dis. 2010, 10, 322. [CrossRef]

45. Barry, M.; Al Amri, M.; Memish, Z.A. COVID-19 in the Shadows of MERS-CoV in the Kingdom of Saudi Arabia. J. Epidemiol. Glob. Health 2020, 10, 1-3. [CrossRef]

46. Lai, J.; Ma, S.; Wang, Y.; Cai, Z.; Hu, J.; Wei, N.; Wu, J.; Du, H.; Chen, T.; Li, R.; et al. Factors Associated With Mental Health Outcomes Among Health Care Workers Exposed to Coronavirus Disease 2019. JAMA Netw. Open 2020, 3, e203976. [CrossRef]

47. Badahdah, A.; Khamis, F.; Al Mahyijari, N.; Al Balushi, M.; Al Hatmi, H.; Al Salmi, I.; Albulushi, Z.; Al Noomani, J. The mental health of health care workers in Oman during the COVID-19 pandemic. Int. J. Soc. Psychiatry 2020, 0020764020939596. [CrossRef]

48. Suryavanshi, N.; Kadam, A.; Dhumal, G.; Nimkar, S.; Mave, V.; Gupta, A.; Cox, S.R.; Gupte, N. Mental health and quality of life among healthcare professionals during the COVID-19 pandemic in India. Brain Behav. 2020, 10, 01837. [CrossRef]

49. Naser, A.; Dahmash, E.; Al Rousan, R.; Alwafi, H.; Alrawashdeh, H.; Ghoul, I.; Abidine, A.; Bokhary, M.; Al-Hadithi, H.; Ali, D.; et al. Mental health status of the general population, healthcare professionals, and university students during 2019 coronavirus disease out-break in Jordan: A cross-sectional study. Brain Behav. 2020, 10, e01730. [CrossRef] [PubMed]

50. Rossi, R.; Socci, V.; Pacitti, F.; Di Lorenzo, G.; Di Marco, A.; Siracusano, A.; Rossi, A. Mental Health Outcomes Among Frontline and Second-Line Health Care Workers During the Coronavirus Disease 2019 (COVID-19) Pandemic in Italy. JAMA Netw. Open 2020, 3, e2010185. [CrossRef]

51. Su, T.-P.; Lien, T.-C.; Yang, C.-Y.; Su, Y.L.; Wang, J.-H.; Tsai, S.-L.; Yin, J.-C. Prevalence of psychiatric morbidity and psychological adaptation of the nurses in a structured SARS caring unit during outbreak: A prospective and periodic assessment study in Taiwan. J. Psychiatr. Res. 2007, 41, 119-130. [CrossRef] [PubMed]

52. Kim, J.Y.; Song, J.Y.; Yoon, Y.K.; Choi, S.-H.; Song, Y.G.; Kim, S.-R.; Son, H.-J.; Jeong, S.-Y.; Choi, J.-H.; Kim, K.M.; et al. Middle East Respiratory Syndrome Infection Control and Prevention Guideline for Healthcare Facilities. Infect. Chemother. 2015, 47, 278-302. [CrossRef] [PubMed]

53. Jeong, H.; Yim, H.W.; Song, Y.-J.; Ki, M.; Min, J.-A.; Cho, J.; Chae, J.-H. Mental health status of people isolated due to Middle East Respiratory Syndrome. Epidemiol. Health 2016, 38, e2016048. [CrossRef]

54. Ahmed, M.Z.; Ahmed, O.; Aibao, Z.; Hanbin, S.; Siyu, L.; Ahmad, A. Epidemic of COVID-19 in China and associated Psychological Problems. Asian J. Psychiatry 2020, 51, 102092. [CrossRef]

55. Cole, A. Two thirds of doctors in UK say the NHS could not cope with bird flu epidemic. BMJ 2006, 333, 674. [CrossRef]

56. Khan, M.U.; Shah, S.; Ahmad, A.; Fatokun, O. Knowledge and attitude of healthcare workers about middle east respiratory syndrome in multispecialty hospitals of Qassim, Saudi Arabia. BMC Public Health 2014, 14, 1281. [CrossRef]

57. Zhang, W.-R.; Wang, K.; Yin, L.; Zhao, W.-F.; Xue, Q.; Peng, M.; Min, B.-Q.; Tian, Q.; Leng, H.-X.; Du, J.-L.; et al. Mental Health and Psychosocial Problems of Medical Health Workers during the COVID-19 Epidemic in China. Psychother. Psychosom. 2020, 89, 242-250. [CrossRef] [PubMed]

58. Bartels, M.; Cacioppo, J.T.; Van Beijsterveldt, T.C.E.M.; Boomsma, D.I. Exploring the Association between Well-Being and Psychopathology in Adolescents. Behav. Genet. 2013, 43, 177-190. [CrossRef] [PubMed]

59. Albert, P.R. Why is depression more prevalent in women? J. Psychiatry Neurosci. 2015, 40, 219-221. [CrossRef]

60. Cornine, A. Reducing Nursing Student Anxiety in the Clinical Setting: An Integrative Review. Nurs. Educ. Perspect. 2020, 41, 229-234. [CrossRef] [PubMed]

61. Xiao, C. A Novel Approach of Consultation on 2019 Novel Coronavirus (COVID-19)-Related Psychological and Mental Problems: Structured Letter Therapy. Psychiatry Investig. 2020, 17, 175-176. [CrossRef]

62. Kmietowicz, Z. Rules on isolation rooms for suspected covid-19 cases in GP surgeries to be relaxed. BMJ 2020, 368, m707. [CrossRef]

63. Tang, B.; Bragazzi, N.L.; Li, Q.; Tang, S.; Xiao, Y.; Wu, J. An updated estimation of the risk of transmission of the novel coronavirus (2019-nCov). Infect. Dis. Model. 2020, 5, 248-255. [CrossRef]

64. Liu, H.; Chen, S.; Liu, M.; Nie, H.; Lu, H. Comorbid Chronic Diseases are Strongly Correlated with Disease Severity among COVID-19 Patients: A Systematic Review and Meta-Analysis. Aging Dis. 2020, 11, 668-678. [CrossRef]

65. Gentili, D.; Bardin, A.; Ros, E.; Piovesan, C.; Ramigni, M.; Dalmanzio, M.; Dettori, M.; Filia, A.; Cinquetti, S. Impact of Communication Measures Implemented During a School Tuberculosis Outbreak on Risk Perception among Parents and School Staff, Italy, 2019. Int. J. Environ. Res. Public Health 2020, 17, 911. [CrossRef]

66. Woodgate, R.L.; Tailor, K.; Tennent, P.; Wener, P.; Altman, G. The experience of the self in Canadian youth living with anxiety: A qualitative study. PLoS ONE 2020, 15, e0228193. [CrossRef]

67. Moreno, E.; Muñoz-Navarro, R.; Medrano, L.A.; González-Blanch, C.; Ruiz-Rodríguez, P.; Limonero, J.T.; Moretti, L.S.; CanoVindel, A.; Moriana, J.A. Factorial invariance of a computerized version of the GAD-7 across various demographic groups and over time in primary care patients. J. Affect. Disord. 2019, 252, 114-121. [CrossRef] [PubMed] 
68. Aiello, A.; Khayeri, M.Y.-E.; Raja, S.; Peladeau, N.; Romano, D.; Leszcz, M.; Maunder, R.G.; Rose, M.; Adam, M.A.; Pain, C.; et al. Resilience Training for Hospital Workers in Anticipation of an Influenza Pandemic. J. Contin. Educ. Health Prof. 2011, 31, 15-20. [CrossRef] [PubMed]

69. Chung, B.P.M.; Wong, T.K.S.; Suen, E.S.B.; Chung, J.W.Y. SARS: Caring for patients in Hong Kong. J. Clin. Nurs. 2005, 14, 510-517. [CrossRef]

70. Bai, Y.X.; Gegan, T.; Hai, H.; Liu, Z.H.; Wang, W.R.; Wang, Z.G. Correlation between psychological changes of the community crowd and the social support in grave public health event. Inner Mong. Med. J. 2005, 37, 295-297. 